\title{
ÉS LA «VARIACIÓ LINGÜÍSTICA SOCIAL" UNA CATEGORIA OPERATIVA PER A LA PLANIFICACIÓ LINGÜÍSTICA DE CORPUS?
}

\author{
IS «SOCIAL LANGUAGE VARIATION» AN OPERATIONAL \\ CATEGORY FOR LANGUAGE CORPUS PLANNING?
}

\author{
Joan Costa Carreras \\ Universitat Pompen Fabra \\ joan.costa@upf.edu
}

Resum: Hem constatat les dificultats d'aprofundir les relacions conceptuals entre la variació social i la funcional, que comencen quan ens preguntem quins factors socials són pertinents per descriure el col-loquial. Creiem que cal tenir en compte, en ordre decreixent, les «adscripcions identitàries» que Block (20I4) analitza: capital lingüístic, capital cultural, edat, gènere, activitat habitual, «habitus/ideologia/actituds», «classe social», ètnia i religió. En aquest context d'incertesa conceptual, no és estrany que la variació social sigui una dimensió sociolingüística tractada inadequadament en la normativa catalana: Badia (1994) confon els termes diastràtic i diafasic i llegint els textos normatius de l'IEC s'hi veu un tractament incoherent, contradictori, imprecís i incomplet de la variació social. La concepció acceptada de gramàtica normativa, que es basa en els judicis socials, queda contradita pel «tractament de la variació» de la GIEC (2016: xxII), que els exclou. Davant d'aquesta contradicció, presentem una anàlisi de com l'IEC exposa la variació social, la funcional $\mathrm{i}$ les relacions entre totes dues. Finalment, encetem el debat de quin seria el tractament pertinent de la variació social per la SF.

Paraules clau: codificació lingüística, estandardització lingüística, Institut d'Estudis Catalans, planificació lingüística de corpus, variació funcional, variació geogràfica, variació social.

Abstract: We have noted the difficulties of deepening the relations between the social and functional diversity, starting when we wonder what social factors are required to describe the colloquial. We take into account, in descending order, the «associated identities» that Block (20I4) analyzes: linguistic capital, cultural capital, age, gender, usual activity, «habitus / ideology / attitudes», «social class», ethnicity and religion. In this conceptual context of uncertainty, it is not surprising that the social variation dimension is inadequately treated in the Catalan prescriptive corpus: Badia (1994) confused the terms diastratic and diaphasic, and reading the Catalan Academy's corpus 
Joan Costa Carreras

Es la «variació lingüistica social» una categoria operativa

per a la planificació lingüistica de corpus?

(IEC) an incoherent, contradictory, inaccurate and incomplete treatment of social variation is found. The accepted conception 'prescriptive grammar', which is based on social judgments, it is contradicted by "treatment of variation" of GIEC (2016: XXII), which excludes them. Given this contradiction, we present an analysis of how the IEC exposes social variation, functional variation and the relationships between them. Finally, we start the debate on what would be the appropriate treatment of social variation by the IEC.

Key words: functional language variation, geographic language variation, Institut d'Estudis Catalans, language codification, language corpus planification, language standardisation, social language variation.

coser es

\section{INTRODUCCIÓ ${ }^{1}$}

Durant tres cursos acadèmics (2015-2016 - 2017-20I8), vam impartir una assignatura sobre els col-loquials catalans. Aquesta experiència ens va fer veure la dificultat d'aprofundir les relacions conceptuals entre la variació social o sociocultural (els trets lingüístics que identifiquen els parlants) i la funcional (els trets lingüístics que s'associen a les situacions comunicatives), que ja Payrató (I996, I998 i 2010) i Boix (1998 i 200I) demostren en general, de manera que parlar en singular de "col-loquial» no és més que una simplificació útil sols en algun moment. Les dificultats comencen quan ens preguntem quins factors socioculturals són pertinents per intentar descriure els diferents col-loquials. Per part nostra, després d'unes quantes lectures (Bernstein 1994, Block 20I4, Bourdieu 200I, Boix 1998 i 200I, Boix \& Vila 1998, Pinto 2016, Ruiz et al. 200I, Sarasa 20I4, Sarasa et al. 20I3) i unes quantes exposicions a l'alumnat, creiem que cal tenir en compte, en ordre decreixent, les següents «adscripcions identitàries» (Block 20I4): capital lingüístic, capital cultural, edat, gènere, activitat habitual, "habitus/ideologia/actituds», "classe social», ètnia i religió.

En aquest context d'incertesa conceptual —a la qual cal afegir l'ambivalència del terme estàndard, concebible com a 'varietat' o com a 'registre'-, no és estrany que hàgim pogut observar que la variació sociocultural és una dimensió sociolingüística tractada inadequadament en el que es pot anomenar la normativa catalana, que, legalment, en paraules del president — per tant, portaveu— de l'Institut d'Estudis

I. Agraïm els valuosíssims comentaris de Núria Alturo, Emili Boix, Pilar Murtra, Neus Nogué, David Paloma, Lluís Payrató, Ester Seguí i Montserrat Sendra, i dels avaluadors de la revista, a diferents versions d'aquest treball, les mancances del qual només ens són atribuïbles a nosaltres. 
Catalans (IEC; Ros 20I6: IX), està constituïda per «la tríada d'obres normatives [...] de la llengua comuna a tota la catalanofonia»: el DIEC2, l'Ortografia catalana i la gramàtica. ${ }^{2}$ I la codificació particular està constituïda per totes les altres obres amb intenció prescriptiva sobre l'ús lingüístic.

D'altra banda, a Costa (2016a) analitzem per què Antoni Maria Badia i Margarit (1994) confon els termes diastràtic i diafâsic. A més, l'IEC (1999: 9) també cau en aquesta confusió:

Per un segon criteri, ara d'estrats o nivells en l'ús de la llengua, distingim entre registres formals i registres informals. Els primers denoten les maneres expressives del registre elevat, pròpies d'un llenguatge asèptic i lògic, gramaticalment més correcte, conceptualment més equilibrat i estèticament més elegant, que en principi caracteritza, entre d'altres, l'estil neutre dels mitjans de comunicació. Els segons corresponen a unes altres maneres de dir, en les quals, sense perdre la correcció, l'equilibri ni l'elegància, aquells qui se n'emparen, o bé no volen renunciar a l'espontaneïtat d'expressió, o bé apel-len a diverses connotacions que es justifiquen per la realitat social i psicològica de cada situació concreta.

I, encara, Ruaix (20I7) dona a entendre que, per ell, les varietats "diastràtiques» són els «nivells d'ús», les varietats funcionals. ${ }^{3}$ I llegint els textos preliminars de la Gramàtica de la llengua catalana (GIEC 2016) i del DIEC2, de l'Institut d'Estudis Catalans (IEC), hem cregut veure-hi un tractament incoherent, contradictori, imprecís i incomplet de la variació dialectal històrica, geogràfica i sociocultural.

Si partim de les concepcions de gramàtica normativa que tres fonts autoritzades expressen, en trobem, en primer lloc, una d'indirectament oficial, Manuel Pérez Saldanya, director de l'Oficina de Gramàtica de la Secció Filològica (SF) de l'IEC i redactor de la GIEC (2016), que defineix la "gramàtica normativa» com a "gramàtica que estableix una sèrie de regles per a delimitar els usos correctes d'una llengua tot seguint, sobretot, els models escrits i les varietats dels grups socioculturalment dominants» (Pérez Saldanya 1998). La segona font oficial és Teresa Cabré, que com a presidenta de la Secció Filològica diu que una "gramàtica descriptiva i alhora prescriptiva valora els usos en funció de les restriccions que aquests usos tenen en el discurs real dels parlants i de la seva valoració social» (GIEC 2016: XIII). ${ }^{4}$ I la tercera font oficial és el $D I E C 2$, que defineix (entre altres accepcions) la «normativa» com a «2 I f. [FL]

2. ¿En quina situació queden els dos volums de la Proposta per a un estàndard oral? Queden invalidats? Cabré (20I6: XIII), Ros 2017 i Cabré 2017 confirmen que la tríada és el corpus normatiu oficial.

3. Lamentablement, en la versió consultable d'aquesta intervenció pública a Internet no es conserva el moment en què ho fa. Donem aquesta informació perquè la vam sentir nosaltres mateixos.

4. I a la p. XIV: la GIEC concep la «llengua com un conjunt d'usos propis i adequats segons les circumstàncies geogràfiques, socials o funcionals en què es donen aquests usos».

Caplletra 67 (Tardor, 2019), p. 93-113 
Joan Costa Carreras

És la «variació lingüistica social» una categoria operativa

per a la planificació lingüistica de corpus?

Conjunt de normes lingüístiques explícites provinents d'una autoritat reconeguda i aplicables a una llengua».

La definició genèrica de Pérez Saldanya (1998) — que coincideix parcialment amb la de Cabré (20I6: XIII) — reconeix el paper de referència dels "grups socioculturalment dominants»; el diccionari esmenta una "autoritat reconeguda», que ho ha de ser per algú —almenys algun grup social—; i la presidenta de la SF esmenta «la valoració social dels parlants» com a criteri per seleccionar «els usos». Per tant, l'«eix» social sembla fonamental en l'establiment d'una gramàtica normativa, d'acord amb aquestes tres fonts directament relacionades amb la SF.

Aquesta assumpció queda contradita quan una altra font oficial, la "Introducció» de la GIEC (20I6: XXII), explicita «el tractament de la variació» que fa i afirma que hi ha «dos eixos de variació principals [...] que les orientacions normatives tenen en compte: la variació geogràfica o territorial i la variació funcional o de registre». I afegeix que «de vegades» també es té en compte l' «eix temporal», és a dir, «la llengua de les generacions més grans i la de les més joves». Cap menció ni al.lusió a la variació sociocultural. 5

Davant d'aquesta contradicció, presentem una anàlisi de com els textos introductoris de la GIEC i certes definicions del DIEC2 exposen la variació que identifica els parlants, la que identifica la situació comunicativa i les relacions entre totes dues. També presentem l'exposició i l'ús que Badia, membre de la SF des de 1968 fins a la seva mort el 20I4, fa de la variació en la seva última gramàtica (Badia 1994), una de les més influents en la normativa catalana, tant oficial com particular. Finalment, encetem el debat de quin seria el tractament pertinent de la variació sociocultural per la SF.

\section{LA VARIACIÓ SOCIOCULTURAL ÉS EXCLOSA DE LA GRAMÀTI- CA MALGRAT LA DECLARACIÓ DE LA PRESIDENTA DE LA SECCIÓ FILOLÒGICA}

La presidenta mateixa (GIEC 20I6:XIV), després d'afirmar que la GIEC concep la «llengua com un conjunt d'usos propis i adequats segons les circumstàncies geogràfiques, socials o funcionals en què es donen aquests usos», quan desplega aquesta afirmació només desenvolupa la «variació geolectal» i la «variació funcional o de registre». ${ }^{6}$

5. De fet, sí: generalment el factor edat és considerat social; però el text que comentem el relaciona amb la varietat diacrònica.

6. I a la p. XV: «una gramàtica que vol ser útil per a totes les situacions i en tot el territori lingüístic». I a Cabré (2017: 9). 
Aquesta omissió de la variació sociocultural es converteix en exclusió explícita, d'entrada en l'organització de l'exposició: el $\$$ III de la «Introducció» es titula «El tractament de la variació» i té com a únics subepígrafs la «Variació geogràfica» (p. XXIII-XXIV) i la "Variació de registre» (p. XXIV-XXVI).

L'exclusió d'aquest tipus de variació es confirma quan la GIEC (20I6: XXV) afirma que

[...] sobretot en els discursos poc formals i d'àmbit privat, hi solen aparèixer expressions que en determinats sectors socials es consideren malsonants o grolleres. Aquesta informació no té fonamentació lingüística, sinó merament social, i això és el que tradicionalment ha portat a considerar vulgars determinats mots [...]. Aquesta gramàtica no fa aquest tipus de consideracions i es limita a donar indicacions de registre en aquests casos.

Glossant aquest fragment pel seu ordre expositiu, en primer lloc creiem que l'expressió «d'àmbit privat» és poc precisa: pot voler dir 'no administrativament oficial' —i aleshores s'oposa a les relacions entre particulars_, o 'familiar' o 'entre amics'. Ens sembla més clar fer una distinció entre relacions socials "primàries» (família i amics) i relacions socials «secundàries» — fora de la família i amics, independentment de si és en l'àmbit oficial (particulars amb l'Administració) o particular (entre particulars: comerciant-client, metge-pacient, etc.).

En segon lloc, crida l'atenció — després de les definicions que hem vist de gramàtica normativa - el mot «merament». El DIEC2 el defineix com «d'una manera mera», i mer com a, «usat davant el nom, pur, sense mescla d'altra cosa». Per tant, el fragment dona a entendre que la gramàtica s'ha d'atenir estrictament a la «fonamentació lingüística» i deixar de banda la "social». ${ }^{7}$ Després d'aquesta afirmació, no és coherent que en els textos introductoris es faci servir constantment el mot social i s'apel.li freqüentment al "prestigi» (v. \$ 7) per acceptar formes, i que no s'entri en la consideració social de la vulgaritat.

L'afirmació «aquesta gramàtica no fa aquest tipus de consideracions i es limita a donar indicacions de registre en aquests casos» és coherent amb la definició que el $D_{I E C}$ fa de les «marques valoratives» popularment i vulgarment (v. $\left.\$ 4\right)$.

7. Com a sinònims de mer, el Diccionari de sinònims (<http://sinonims.iec.cat/sinonims_cerca_sin. asp?pclau2 $=$ mer\&offset $=320>)$ dona entre altres: pur, únic, simple, sol, net, elemental. L'adverbi merament és sinònim, segons nosaltres, de estrictament, només, pur, únicament, simplement, solament, netament, elementalment. Creiem lícit plantejar-se si aquest conjunt lèxic no podria arribar a ser interpretat com a vehiculador d'una certa actitud de distanciament respecte del contingut de l'adjectiu modificat per aquests adverbis —o fins i tot, d'un cert menyspreu: la idea de simplicitat sovint és percebuda com una mancança enfront de la complexitat.

Caplletra 67 (Tardor, 2019), p. 93-113 
Joan Costa Carreras

És la «variació lingüistica social» una categoria operativa

per a la planificació lingüistica de corpus?

\section{LA NORMATIVA NO DONA INFORMACIÓ SOBRE LA IDENTIFICA- CIÓ SOCIOCULTURAL DE CERTS MOTS CLARAMENT ASSENTADA ENTRE ELS PARLANTS I ALTRES FONTS}

El DIEC2 no atribueix cap marca «valorativa» als mots mare/pare, mamalpapa i mamà/papà: ni recull les expressions fill de mamà o fill de papà. ${ }^{8}$ En canvi, el Diccionari català-valencià-balear (DCVB), el Diccionari etimològic i complementari de la llengua catalana (DECat), el diccionari.cat i el Diccionari descriptiu de la llengua catalana $(D D L C)$, sí — com veurem a continuació.

El Diccionari català-valencià-balear (<http://dcvb.iec.cat/results.asp>) el 1962 ja dona força informació:

$\operatorname{mama} f . \|$ I. Mare (or., occ., alg.) [...] Eтім.: del llatí mamma, mat. sign. I, 2.

mamà $f$. Mare, en el llenguatge modern; cast. mamá. Sentiu lo que ha dit la mamà?, Vilanova Obres, Iv, 249. Eтiм.: pres del fr. maman, mat. sign.

papa $m$. || I. Pare, en llenguatge infantil. Papa Satan, papa Sathan reguard, Febrer Inf. vII, I. Es diu papa (=pare), per oposició a mama (=mare), en el llenguatge infantil de Barcelona i de gran part de Catalunya; al País Valencià i a les Balears predomina i es va estenent cada vegada més la forma papà. [...] Eтiм.: del llatí papa, mat. sign.

papà Nom equivalent a "pare», originàriament en el llenguatge infantil, però estès modernament fins i tot en el llenguatge dels adults, sobretot de les capitals i poblacions grans; cast. papá. En adonar-se del seu papà, Pons Com an. 78. Loc. -Papà, mamà i sopetes sense oli; Papà, mamà $\boldsymbol{i}$ arengades amb un tovalló: es diu per escarnir els qui, essent pobres, volen imitar el llenguatge i modals dels rics (Empordà). Fon.: pəpá (or., men.); papá (occ., val., mall.). Етім.: del llatí pappu, 'pare', però per mediació del fr. papa, cast. papá.

En resum, doncs, el $D C V B$ dona informació cronològica («llenguatge modern»), geogràica ( $p a p a$, en el llenguatge infantil de Barcelona i de gran part de Catalunya; al País Valencià i a les Balears predomina i es va estenent cada vegada més la forma papà.») i sociocultural, ja que, en termes de Labov (1994: 83, hi ha hagut un "canvi en la comunitat» en passar papà als adults ("papà Nom equivalent a "pare», originàriament en el llenguatge infantil, però estès modernament fins i tot en el llenguatge dels adults») i és un fenomen urbà («sobretot de les capitals i poblacions grans»).

Més modernament, el DECat dona les informacions següents:

MAMA [...] com a vocatiu dirigit a la mare per les criatures i nois havia estat general fins endavant del S. XIX i resta i restarà en ús: a finals del S. XIX molta gent de la classe alta els ensenyà l'afrancesat mamà (a Mall. mamai); però àdhuc a Barcelona, i en el primer quart del xx, ho mantenien bastantes famílies, rebutjant mamà com una afectació francesa i castellana [...].

8. Buscades a les entrades mamà, papà i fill. 
PAPA [...] fou el mot del llenguatge de sempre per anomenar 'el pare', en el parlar de les criatures i dels adults que hi tractaven; papà s'introduí en el S. XIX com a francesisme de certes famílies, mirat per la majoria com una francesada de mal gust; aviat guanyà terreny (Lab. 1864), per igual, en les capitals dels quatre països de la llengua, si bé a Bna. s’hi resistien encara c. 1920 les famílies cultes i benestants més tradicionalistes - liberals o no- (a casa meva ho vaig sentir sempre ridiculitzat), però ja estava quasi generalitzat en aquells anys (consigna adoptada per «En Patufet", JMFolch i Torres i el seu cercle, i literatura infantil en general), fora de la menestralia, si bé pertot ha restat papa en l'ambient rural i de les viles, única forma verament catalanesca.

Dualisme lingüístic social, mai regional [...]. Fets paral.lels en mamà. Molt més locals les alteracions pai i papai [1835: DAg.; recordo que aquesta era usada per alguns segarretes carrinclons i escarnida a Bna., c. I929; mall., men.] [...].

La novetat d'aquest diccionari respecte al $D C V B$ és la informació que papa era usat «en el parlar [...] dels adults que [...] tractaven [amb] les criatures»: un registre dependent del destinatari.

D'altra banda, el diccionari.cat (<http://www.diccionari.cat/>) dona menys informació:

mama [I507; del ll. mamma, íd.] $f_{\mathbf{I}}$ Terme infantívol, afectuós per a designar la mare.

mamà [variant de mama] $[p l-\grave{a} s] f$ Terme infantívol, afectuós, per a designar la mare.

papa [c. I240; del ll. papas, ll. td. papa, i aquest del gr. pápas 'pare; bisbe; Papa', formes de creació expressiva infantil] $m$ I $I$ Terme afectuós per a designar el pare, usat generalment en el llenguatge infantil. $2 p l$ Pare i mare; pares.

papà [s. XIX; variant de la forma infantil $p a p a^{I}$, segurament d'influx fr. modern] [ $p l$-às $] m \mathbf{I}$ Terme infantívol, per a designar el pare. $2 p l$ Pare i mare; pares.

fill [...] 8 fill de papà Jove de família acomodada a qui els seus pares concedeixen tots els capritxos sense haver-se d'esforçar.

Atribueix mama/papa i mamà/papà al «llenguatge infantil» sense precisar més; seria, doncs, un terme generacional, el que Labov (1994: 83) anomena «age grading». Només en la locució fill de papà es fa referència, per metonímia, a la situació econòmica, «acomodada», de qui fa servir el mot papà.

I més modernament el Diccionari descriptiu de la llengua catalana (<http://dcc. iec.cat/ddlcI/scripts/indexA.asp?ini=mama $>$ ) dona la informació següent:

mamà

LOCUCIONS

de mamà loc. adj. I. [ $\mathrm{N}_{\mathrm{I}}$ LOC] ( $\mathrm{N}_{\mathrm{I}}$ [humà]) [Algú] aviciat perquè prové d'una família acomodada. Als nens de mamà com tu, que em tiren en cara de tenir només una americana d'hivern $i$ em diuen que els fa vergonya de sortir amb mi tal com vaig, primer els faig saber que em fan fastic [...]. [Bonet (1969): N, p. I04] $\mathrm{i}$. 
Joan Costa Carreras

És la «variació lingüistica social» una categoria operativa

per a la planificació lingüistica de corpus?

A papà no recull fill de papà; però sí a fill:

fill de papà loc. nom. I. Jove que viu a costa de la situació benestant de la seva família. El noi Casajoana s'havia afaitat i duia roba nova. Semblava més tranquil i el seu posat era indiferent, típic d'un fill de papà de casa bona. [Fuster (1984): N, p. IO4] $]^{\mathrm{i}}$.

Com a resum de la informació sociocultural continguda en aquestes tres fonts no oficials, només cal que rellegim el que hem dit més amunt de la informació del $D C V B$ i del DECat.

D’altra banda, Emili Boix (I998: I49) ${ }^{9}$ en diu el següent:

En alguns aspectes, la variació sociolectal barcelonina mostra una distribució tallant. Recentment, Boix (en «preparació $a »$ ) ha analitzat la variació social de les variants de mare, com a vocatiu: mama/mamà/mare, en català central barceloní. En una enquesta a 207 subjectes de primera llengua catalana de la zona barcelonina en els anys I994 a 1996, un 71.4 \% (n:I48) afirmaren que usaven mama en la seva socialització primària, un $24.6 \%$ mare (n: 5I ) i $4.8 \%$ (n: Io) mamà. Aquesta darrera variant era usada solament per sectors de classe mitjana-alta o alta, gairebé sempre de Barcelona ciutat, els quals estigmatitzaven la variant, mama. Per contra, la variant mamà era estigmatitzada per la resta de parlants: fins i tot la majoria la consideraven una variant aliena al català. En els anys noranta contrasta la tria majoritària de mama i mare (i el rebuig de mamà), en la publicitat, en els llibres de text i en el model de català col-loquial vehiculat a la CCRTV, amb l'ús generalitzat de mamà (i el rebuig de mama) en publicacions infantils catalanes de classe mitjana abans de la guerra civil. Paloma (I995) assenyala que la Comissió de Normalització Lingüística de la CCRTV «assenyala que papa i mama només són vàlides en llenguatge infantil». Mamà és considerada "forma molt connotada» i s'aconsellen les formes més neutres socialment: mare $i$ pare.

Hi ha, doncs, una distribució sociocultural en les relacions socials primàries: mamà/papà és usat per «sectors de classe mitjana-alta o alta, gairebé sempre de Barcelona ciutat» i és "estigmatitzada» per la resta de barcelonins. Aquells sectors estigmatitzen al seu torn la variant mama/papa. I un «agent» d'orientació normativa pública, la CCRTV, recull aquesta percepció. En canvi, el DIEC2 no dona aquesta informació, que pot resultar pertinent per als usuaris. Per tant, d'acord amb Boix \& Vila (1998: 55), seguint William Labov, mama/papa i mamà/papà són «estereotips» («fenòmens reconeguts pels membres de la comunitat que serien objecte de comentaris explícits i fins i tot de correcció»).

9. El treball es va publicar a Boix (2007). 


\section{ES CONFONEN ELS TERMES RELATIUS A LA VARIACIÓ SOCIOCUL- TURAL AMB ELS DE LA VARIACIÓ FUNCIONAL}

La GIEC (20I6: XXII) afirma que «quan [les] solucions concurrents estan sotmeses a variació geogràfica o social, el text explicita, quan és possible precisar-ho, la pertinença de les variants als dialectes o als registres respectius, o a la combinació d'uns amb altres. [...]»

El lector es veu conduït a un paral.lelisme discursiu: primer s'esmenta «la variació geogràfica» i la "social»; després sembla clar que els «dialectes» són conceptes lligats a la variació geogràfica i, per tant, per eliminació, que els «registres» es relacionen amb la variació... «social». ¿Fan servir registre com a 'sociolecte / varietat sinstràtica / diastràtica' (Coseriu 198I)? Si fos així, seria una mostra més de la confusió entre variació sociocultural i funcional — com la de Badia de 1994 (v. $\$$ 9), membre de la Comissió de Gramàtica, i Ruaix (20I7).

¿No és un contrasentit afirmar, d'una banda, que certes «solucions concurrents estan sotmeses a variació geogràfica o social», però, del'altra, que no sempre «és possible precisar-ho»? S'al-ludeix a la variació «lliure»? La resposta ha de ser que no, perquè si fos «lliure» seria perquè no està "sotmesa»; per tant, tampoc no estaria sotmesa a variació diatòpica o diastràtica.

També hi ha un cas de confusió entre variació sociocultural i variació funcional en un altre document oficial, el $D I E C 2$, en parlar de les «marques valoratives i d'àrea temàtica» (<http://dlc.iec.cat/instruccions2_4.html>). S'hi afirma que «les marques valoratives donen informació sobre el registre d'alguns mots (POP[ULARMENT]., VULG[ARMENT].).» ${ }^{10}$ D'acord amb això, els adjectius popular i vulgar serien de l'àmbit de la variació funcional, dels registres. Una manera de comprovar-ho és mirar-ne les definicions al mateix DIEC2. Comprovarem també quina definició dona de registre i estil, i com a contrast quina definició dona de dialecte i varietat. ${ }^{11}$

Un «registre» és «IO $2 \mathrm{~m}$. [FL] [una v] arietat funcional d'una llengua definida d'acord amb els factors de la situació comunicativa, com ara el nivell de formalitat, el tema del qual es parla, etc.»

Pel que fa l'estil, el DIEC2 dona les següents definicions pertinents per als nostres objectius:

estil $[\ldots]$

2 I m. [LC] [FLL] Manera d'expressar el pensament en el llenguatge oral o en l'escrit. L'estil d'un escriptor. La teoria clàssica dels tres estils: baix, mitjà i elevat [...]

Io. Concepció coherent amb el que hem vist al § 2 sobre els vulgarismes a la GIEC (2016).

II. El DIEC2 no entra el mot sociolecte. 
Joan Costa Carreras

És la «variació lingüistica social» una categoria operativa

per a la planificació lingüistica de corpus?

$24 \mathrm{~m}$. [FL] Varietat lingüística caracteritzada per un determinat nivell de formalitat, l'ús de la qual és apropiat en certs contextos interactius o en determinats àmbits d'ús.

3 I m. [LC] [FLL] [AR] Manera característica d'execució de les obres d'un artista, d'una escola, d'una nació, etc. L'estil de Palestrina. L'estil gòtic.

$32 \mathrm{~m}$. [LC] Manera característica de fer, de presentar, les coses. L'estil italià de cantar.

$33 \mathrm{~m}$. [LC] Manera característica d'ésser i de fer.

Seguint l'ordre d'aquest diccionari, es poden fer les observacions següents:

L'accepció 2.I relaciona estil alhora amb la variació identificadora dels parlants i de la situació comunicativa: dona un exemple de la primera («L'estil d'un escriptor») i de la segona («La teoria clàssica dels tres estils: baix, mitjà i elevat»). El primer exemple s'inclou, a parer nostre, dins de la variació lingüística professional.

L'accepció 2.4 relaciona estil només amb la variació identificadora de la situació comunicativa, i és sinònim de 'registre' (accepció IO.2).

Les accepcions 3.I-3.3 relacionen estil només amb la variació identificadora de les persones.

Per tant, un dels mots més usats en parlar de variació lingüística, tant es relaciona amb la variació sociocultural com amb la funcional: en aquest diccionari però també en d'altres. ${ }^{12}$ Creiem que és un indici més de la dificultat de relacionar adequadament la variació sociocultural amb la funcional.

Una «varietat» és " 5 f. [FL] [un ú]s específic que es fa d'una llengua d'acord amb la procedència geogràfica, històrica o social dels parlants o amb la funció comunicativa, i que es caracteritza per una determinada concurrència de variants lingüístiques.»

I un «dialecte» és «I $m$. [LC] [FL] [una v]arietat geogràfica, històrica o social d'una llengua, associada a la procedència dels parlants.»

D'acord amb la definició del DIEC2, doncs, les marques "popularment» i «vulgarment» estan relacionades «amb els factors de la situació comunicativa, com ara el nivell de formalitat, el tema del qual es parla, etc.» Si consultem per ordre alfabètic les definicions dels adjectius que les originen, hem de mirar primer popular; el DIEC2 en diu el següent:

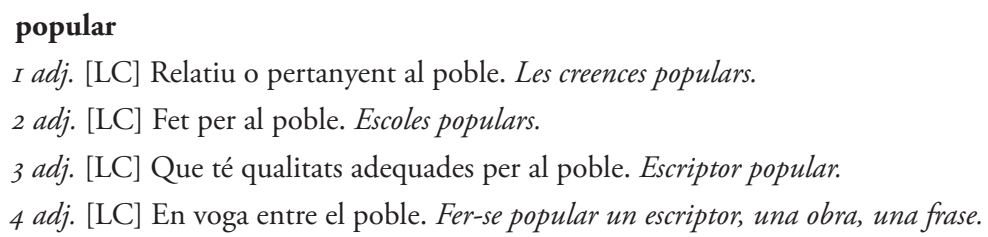

I2. V., p. ex., el diccionari.cat (<http://www.diccionari.cat/lexicx.jsp?GECART=0059230 >), que n'amplia la polisèmia, p. ex., en esmentar els «llibres d'estil». 
En totes quatre definicions es remet al concepte de poble, que el mateix diccionari defineix — per al que ens interessa- com segueix:

\section{poble}

3 I $m$. [LC] [AN] Conjunt de ciutadans que constitueixen les classes socials no dominants. Gent del poble. La revolta del poble contra el poder de la burgesia.

32 [LC] [HIH] baix poble [o poble menut] El grup més baix en l'estratificació social.

És clar, arran d'aquesta consulta, que popular és un concepte sociocultural: identifica «les classes socials no dominants» $\mathrm{i}$ «els grups baixos en l'estratificació social».

Si passem a vulgar, d'entrada cal no perdre de vista que (v. \$2) la GIEC (2016: $\mathrm{XXV}$ ) afirma que la consideració de certes expressions com a «malsonants o grolleres» té "fonamentació merament social, i això és el que tradicionalment ha portat a considerar vulgars determinats mots. Aquesta gramàtica no fa aquest tipus de consideracions i es limita a donar indicacions de registre en aquests casos». La consideració que el DIEC2 fa d'aquesta marca valorativa com a marca de registre hi és coherent. Les definicions del diccionari són les següents:

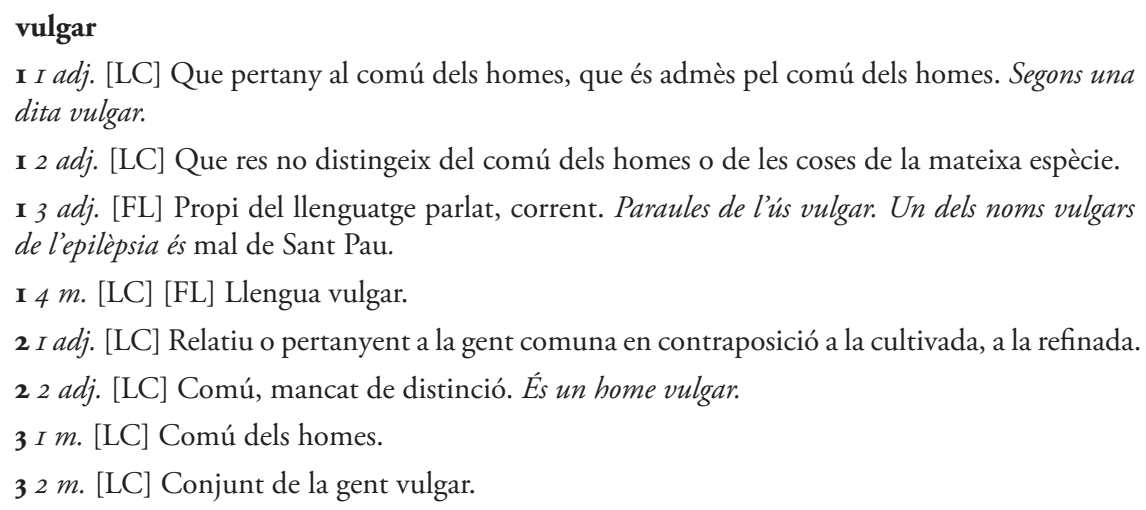

En les subaccepcions I i 3, vulgar identifica el «comú dels homes», concepte que en la 2 s'oposa a la gent "cultivada», «refinada» o "distingida». Així, mentre que popular identifica els grups no dominants o baixos, vulgar identifica els no cultivats, refinats o distingits; és una oposició segons el tipus o grau d'educació. Són característiques diferents, que, no cal dir-ho, podrien caracteritzar simultàniament un parlant o un grup de parlants.

Sembla clar, doncs, que tant popular ('baix, no dominant') com vulgar ('no cultivat, refinat o distingit') identifiquen grups socioculturals i no pas situacions comunicatives —com ja afirma Boix 200I: I83. 
Joan Costa Carreras

És la «variació lingüistica social» una categoria operativa

per a la planificació lingüistica de corpus?

Un adjectiu que sovint s'usa com a sinònim de popular és familiar. El DIEC2 en diu el següent: «familiar 4 adj. [LC] [FL] Semblant a allò que s'estila entre persones de la mateixa família, s'aplica especialment al tracte senzill, sense compliments, al llenguatge, a l'estil, a les frases, etc., corrents, col-loquials.»

Aquests últims mots hi són definits com segueix:

corrent [...] 62 adj. [LC] Generalment acceptat, admès per l'ús comú, pel costum. Una opinió corrent. El sentit corrent d'un mot.

col.loquial adj. [LC] [FL] Propi de la conversa familiar, no literari. Llenguatge col.loquial.

El primer és un terme de l’àmbit sociocultural. En el segon, l’apel-lació a la «no literarietat» ens porta a consultar la definició de literari com a 'no familiar'. Segons el DIEC2: «literari», per al que ens interessa aquí, és «[r]elatiu o pertanyent a les belles lletres, a la literatura. Estudis literaris. Crítica literària. Acadèmia literària.»

Per no deixar cap mot sense comprovar, mirem lletres: «lletra [...] 7 I f. pl. [FLL] [AR] [FL] Disciplines humanístiques, especialment la literatura. Conrear les lletres, les belles lletres. Un home de lletres. La gent de lletres. Una facultat de lletres.»

Es comprova la metonímia i la consignació de l'expressió «belles lletres». Per tant, el llenguatge col-loquial és el que no té pretensió estètica, concepte que es pot relacionar mínimament amb el concepte de «tenor», propi de la variació funcional (Payrató 1996).

Ens trobem davant d'unes interremissions circulars entre familiar i col.loquial: el primer es defineix bàsicament pel que en variació funcional s'ha anomenat el «to» de la formalitat («entre persones de la mateixa família, sense compliments») i el segon s'oposa a «literari», en virtut del «tenor» funcional. Tots dos, doncs, a partir del DIEC2, pertanyen a l'àmbit funcional de la variació.

Pel que fa a sociolecte, el Termcat (http://www.termcat.cat/ca/Cercaterm),$^{13}$ en diu el següent: «sociolecte $<$ Sociolingüística $>$ Varietat social d'una llengua. Nota: Els parlants d'un sociolecte normalment comparteixen unes determinades característiques socioeconòmiques i educatives.»

Sembla, per tant, clara la contradicció que hi ha al $D I E C 2$ entre

a) considerar "popularment» $\mathrm{i}$ «vulgarment» marques valoratives de «registre» $\mathrm{i}$

b) el caràcter sociocultural de les definicions de popular ('de classe no dominant, baixa') i vulgar ('no cultivat, refinat o distingit').

I3. Segons la «Presentació» del Termcat (<http://www.termcat.cat/ca/El_TERMCAT/Centre_De_Terminologia/>), l'IEC el va crear el 1985, juntament amb la Generalitat de Catalunya, i hi aporta el paper referencial en la normalització terminològica. Per tant, és lícit deduir que l'IEC es corresponsable d'aquesta definició. 
El DIEC2 caracteritza popular per la manca de poder o d'hegemonia socials i vulgar per mancances en l'educació.

\section{ELS FACTORS SOCIOCULTURALS SÓN FONAMENTALS EN LA INTERVENCIÓ DE LA GIEC SOBRE LA VARIACIÓ DIATÒPICA}

Segons la GIEC (2016: XXIII),

[e]ls trets més consolidats i prestigiosos de les varietats geogràfiques habitualment es consideren vàlids dins de la llengua general formal, sobretot si són compartits per diverses àrees dialectals [...]

Aquesta gramàtica [...] dona compte de les variants més representatives de cada parlar que han assolit prestigi $[\ldots]$

Els mots "consolidats» $\mathrm{i}$ «representatives», creiem que s'han d'entendre com a sinònims de 'tradicionals', concepte clarament propi de la variació sociocultural. Si el "prestigi» és l'«ascendent, influència, deguda a èxits anteriors, a la reputació adquirida» $(D I E C 2)$, de seguida s'entén que el prestigi és el dels grups socioculturals que tenen aquestes formes com a característiques. És un concepte de variació sociocultural: implica que hi ha variants no prestigioses (les produïdes pels grups no prestigiosos). Seria una demostració que, en la fase de codificació, la variació sociocultural és una subcategoria imprescindible de la de variació diatòpica.

\section{ELS FACTORS SOCIOCULTURALS SÓN FONAMENTALS EN LA DEFI- NICIÓ DE LA VARIACIÓ FUNCIONAL}

Segons la GIEC (2016: XXV), «[e]l concepte de formalitat es basa sobretot en el tipus de relació que el discurs estableix entre [...] els rols socials que assumeixen els interlocutors [...]. Els indicadors més visibles de formalitat són les formes de tractament $[\ldots](\$ 8.2 .2)[\ldots] .{ }^{14}{ }^{\prime}$

Deixant de banda la reïficació o «objectivisme» del discurs — ¿no són els parlants els qui ho fan?-, es fa servir l'adjectiu social però no es fa cap referència

I4. Resta per fer un buidatge dels passatges de la GIEC (2016) en què l'argumentació de la «validesa normativa» de certes variants enfront d'altres es fonamenta en criteris relacionables amb la variació sociocultural. P. ex.: «Les oracions amb verbs ditransitius tendeixen a admetre la presència del pronom feble de tercera persona duplicant el complement indirecte, especialment en valencià i les zones urbanes del Principat de Catalunya, sobretot en la parla dels joves» (GIEC 20I6: 685).

Caplletra 67 (Tardor, 2019), p. 93-113 
Joan Costa Carreras

És la «variació lingüistica social» una categoria operativa

per a la planificació lingüistica de corpus?

a la variació sociocultural. Cal concloure, doncs, que la formalitat és la cruilla entre la variació sociocultural i la funcional.

D’altra banda, el president de l'IEC afirma (2016: X) que la GIEC «té en compte la variació lingüística al llarg del territori, els diferents nivells d'ús i la diversitat intrínseca d'una llengua que és alhora antiga i moderna, pròpia del mercat i de l'aula, de l'estrada i de la llar.»

Costa d'entendre a què es refereix per "diversitat intrínseca», diferent de la que es dona «al llarg del territori» i la constituïda pels «diferents nivells d'ús»: ¿̨la variació no correlacionable amb factors geogràfics ni funcionals? ¿La deguda a factors «interns»? A banda d'això, l'interessant és analitzar com es classificarien les metonímies «mercat», «aula», «estrada» $\mathrm{i}$ «llar». En principi remeten a situacions comunicatives, com sempre amb un gran pes del grau de formalitat, però lligades a sectors professionals: serien metonímies bàsicament funcionals, doncs.

\section{LA VARIACIÓ LINGÜÍSTICA SOCIOCULTURAL NO S’ESMENTA EXPLÍCITAMENT, PERÒ S’USA IMPLÍCITAMENT}

Tal com ja hem dit, a la p. XXII, la GIEC (20I6) explicita «el tractament de la variació» que s'hi fa i afirma que hi ha "dos eixos de variació principals [...] que les orientacions normatives tenen en compte: la variació geogràfica o territorial i la variació funcional o de registre. [D]e vegades [l'] eix [...] temporal [...] també, entre la llengua de les generacions més grans i la de les més joves». No s'hi fa cap menció de la variació sociocultural, tot i que s'usa almenys 36 vegades el mot social en els textos introductoris i almenys I4 vegades s'apel.la al «prestigi» (v. $\$ 5$ ).

En canvi, a la «introducció» del DIEC2 («3. La variació dialectal: El Diccionari de tots els territoris de llengua catalana»: <http://dlc.iec.cat/introduccio2_3.html>), sí que s'esmenta la variació sociocultural:

Construir la preceptiva d'una llengua implica inesquivablement triar, en un procés particularment compromès i difícil, en què cal ésser conscients que tota la variació no hi cap, ni la geogràfica, ni la social, ni la individual. La tasca de selecció suposa el sacrifici de moltes solucions, que, tanmateix, són vives i objecte de consideració i estudi en la dialectologia, en l'anàlisi dels registres, etcètera. Sobretot pel que fa a la inclusió de les formes que singularitzen territorialment els parlars catalans, s'ha d'ésser especialment sensible, perquè, dels resultats, en depèn que el col-lectiu senti com a seves les opcions normatives elegides; cap dels grans dialectes no pot ésser ignorat ni menyspreat, a partir dels criteris de l'extensió i la vitalitat de les formes i també de llur caràcter emblemàtic en el territori corresponent. [...] 
Però, malgrat ser esmentada explícitament, la variació sociocultural torna a quedar diluïda en un "etcètera» — a diferència de la geogràfica i la funcional—: "solucions, que, tanmateix, són vives i objecte de consideració i estudi en la dialectologia, en l'anàlisi dels registres, etcètera [...]». Només és al.ludida indirectament: ${ }^{15}$ "el col.lectiu senti com a seves les opcions normatives elegides; cap dels grans dialectes no pot ésser ignorat ni menyspreat, a partir dels criteris de l'extensió i la vitalitat de les formes i també de llur caràcter emblemàtic en el territori corresponent». El mot dialectes només pot ser entès aquí com a sinònim de 'varietats diatòpiques'.

\section{LA NORMATIVA TÉ EN COMPTE CERTES «ADSCRIPCIONS IDENTI- TÀRIES"}

El DIEC2, en el «Pròleg» («2. Diccionari general i lèxic d'especialitat»; <http:// dlc.iec.cat/introduccio2_2.html>), diu:

La mobilitat social interna i externa duu implícit l'acostament vinculant de les persones a les múltiples activitats de la vida social: laborals, lúdiques o de qualsevol altra mena. Aquest fenomen suposa la destrucció de fronteres entre espais reservats fins ara a minories molt reduïdes. Els mitjans de comunicació, especialment els lligats amb la cibernètica, han tingut i tenen una funció decisiva en aquest sentit.

[...] I l'Institut d'Estudis Catalans ha heretat i no ha abandonat mai les línies del Mestre; ben al contrari, gràcies a una millor coneixença de la realitat variacional de la llengua, ha eixamplat constantment la seva presència en el diccionari normatiu, a partir dels criteris de la tradició i la popularitat, de l'extensió territorial, de facilitar la substitució d'una interferència, de l'aprofitament de matisos, de la coherència estructural.

I, més endavant («4. Ideologia i llengua» [<http://dlc.iec.cat/introduccio2_4. html>]), afirma que

[...] s'ha prosseguit la labor de desideologització empresa ja en la primera edició damunt el corpus elaborat per Pompeu Fabra, és a dir, de descarregar-les tant com s'ha pogut i sabut de condicionaments produïts per determinades visions de la realitat que han estat o que són hegemòniques en la cultura $[\ldots]$.

És evident que determinats camps semàntics es presten més facilment, en sigui hom conscient o no, a la submissió a prejudicis; l'àmbit de la religió és un dels que més reclamen l'actitud distant del lexicòleg i del lexicògraf, que permeti un tractament neutral dels conceptes que hi fan referència, directament o indirectament. [...] sexe. $[\ldots]$

S’ha mirat d'afinar encara més en el tractament igualitari de les persones, al marge del

I5. Marquem les al.lusions amb cursives. 
Joan Costa Carreras

És la «variació lingüistica social» una categoria operativa

per a la planificació lingüistica de corpus?

Per tant, la SF és conscient de la influència de les ideologies en l'elaboració de documents normatius i ho concreta en fenòmens sociològics com la religió o el sexe.

\section{BADIA (1994) IGNORA EXPLÍCITAMENT LA VARIACIÓ SOCIOCUL- TURAL, USA DIASTRÀTIC PER DIAFÀSIC, PERÒ L'USA IMPLÍCITAMENT}

Una obra normativa no oficial, Badia (1994), titula la seva gramàtica com a «descriptiva, normativa, diatòpica, diastràtica». Aquesta última característica és presentada com a «vertical», amb

- $\quad$ el «registre literari més elevat» al capdamunt («NI»),

- $\quad$ seguit en ordre descendent dels nivells «corrent $\left(\mathrm{N}_{2}\right)$ i

- col.loquial $\left(\mathrm{N}_{3}\right)_{)}$.

Per tant, en contra de la tradició instaurada per Coseriu (198I), fa servir el terme diastràtic (relatiu a l'estratificació social) en comptes de diafásic (relatiu a la variació funcional). Malgrat això, en el fragment següent combina adequadament les dues perspectives (Badia 1994: 453-454):

[...] en el llenguatge corrent (modalitat oral), la forma lo és pràcticament universal en l'ús espontani de la llengua: no estranya ningú i ningú no s'hi sent estrany. [...] a molta gent de formació poc sòlida li sembla impossible que els girs al-ludits [amb $l o]$ puguin ésser reemplaçats per d'altres d'equivalents.

[...] la llengua escrita evita [...] l'article neutre. Ara bé, aquest tractament es fa per formació escolar i per disciplina. Ho prova que a zelosos conreadors de la llengua, que no posen mai un *lo en allò que escriuen, se'ls escapa a cada pas la nefanda forma quan enraonen despreocupadament $[\ldots]$

Fa servir els termes següents relatius a la variació que identifica la situació comunicativa (la funcional):

a) «llenguatge corrent» vs. «l'ús espontani»: són relatius a la formalitat mitjana vs. formalitat baixa;

b) «modalitat oral» / «quan enraonen» vs. «llengua escrita» / «allò que escriuen»: són relatius al mode o canal.

I fa servir els termes següents relatius a la variació que identifica els parlants (la sociocultural): 
a) «universal» / «no estranya ningú i ningú no s’hi sent estrany»: són relatius a tota la comunitat lingüística;

b) «molta gent de formació poc sòlida» vs. "per formació escolar•: són relatius al grau d'instrucció;

c) "per disciplina»: és relatiu a una actitud (psicologia social del llenguatge);

d) «zelosos conreadors de la llengua»: és relatiu a un grup professional.

\section{CONCLUSIONS I PROPOSTES DE RECERCA}

A la «Introducció» d'aquest treball dèiem que «llegint els textos preliminars de la Gramàtica de la llengua catalana (GIEC 20I6) de l'Institut d'Estudis Catalans (IEC), hem cregut veure-hi un tractament incoherent, contradictori, imprecís i incomplet de la variació dialectal, entesa com el conjunt de trets que identifiquen els parlants des dels punts de vista històric, geogràfic i sociocultural.»

Els títols dels apartats pretenen ser una demostració argumentada d'aquesta creença inicial. Així, hem confirmat els defectes dels documents normatius oficials que crèiem d'entrada trobar-hi:

a) La contradicció interna entre els documents de la Secció Filològica pel que fa al tractament de la variació sociocultural queda demostrada pel fet que és exclosa de la gramàtica, malgrat la declaració de la presidenta de la Secció Filològica.

b) La insuficiència de la informació sobre aquesta dimensió de l'ús, la confirma que la «tríada normativa» no dona informació sobre la identificació sociocultural de certs mots clarament assentada entre els parlants i altres fonts.

c) La imprecisió conceptual, la demostra que es confonen els termes relatius a la variació sociocultural amb els de la variació funcional.

d) La incoherència, la deixa clara, d'una banda, el fet que els factors socioculturals són fonamentals en la intervenció en la variació diatòpica i en la definició de la variació funcional que fa la GIEC, tot i que no tracta sistemàticament la variació sociocultural. D'altra banda, no esmentar explícitament la variació lingüística sociocultural però usar-la implícitament posa de manifest que és necessària per a la codificació malgrat no ser tractada sistemàticament.

Tanmateix, la institució normativa té l'encert de tractar explícitament de certes adscripcions identitàries, com la religió i el sexe al DIEC2. 
Joan Costa Carreras

Es la «variació lingüistica social» una categoria operativa

per a la planificació lingüistica de corpus?

Per tant, la resposta a la pregunta del títol, «és la "variació lingüística sociocultural" una categoria operativa per a la planificació lingüística de corpus?», ha de ser, de moment, negativa. Arribats en aquest punt, cal preguntar-se en quina mesura és imprescindible solucionar aquestes mancances pel que fa al tractament de la variació sociocultural en la codificació del català.

En aquest sentit, en treballs successius ens proposem de tractar qüestions com les següents:

a) Fins a quin punt són pertinents per a l'estandardització les «adscripcions identitàries» (Block 20I4: 95), com el capital lingüístic, el capital cultural, l'edat, el gènere, l'activitat habitual, l'«habitus/ideologia/actituds», la "classe social», l'ètnia, la religió, etc.

b) Quins d'aquests paràmetres són necessaris i suficients per definir el "parlantoient ideal» que la SF hauria d'establir com el seu destinatari? ${ }^{16}$

c) Tracta la $\mathrm{SF}$ adequadament aquestes «adscripcions identitàries»?

d) Tracta la SF adequadament la relació de les «adscripcions identitàries» amb els factors que afecten l'ús segons la situació comunicativa?

e) En un «marc de condicions sociolingüístiques favorables» (Costa 20I6b), és possible la «diaglòssia» (Auer 2005)?

f) Per a una implantació acceptable de la normativa, cal fomentar el «sesquidialectalisme» en la catalanofonia / entre els destinataris de la GIEC, com a 'acceptació per cada grup social de les variants «adequades en els registres formals» pròpies d'altres grups'?

g) Quin tractament fa la SF dels collloquials fingits?

h) Quin és l'estatus teòric dels col-loquials com a varietats alhora funcionals i socioculturals?

i) Cal aclarir la categorització dual de certes denominacions relatives a la variació - per exemple la del mot estil i la del sintagma llibre d'estil (Costa 1996) —, com a conceptes lligats a la identificació dels emissors i com a concepte funcional?

j) Quin desenvolupament cal fer de la «destresa interpretativa» que Cabré (20I6: XV) demana a l'usuari de la GIEC — que potser hauria d'incloure l'assumpció d'un cert «sesquidialectalisme»—?

16. A Costa (en premsa) n'assagem una definició: «és destinatària de la normativa tota persona que, d'acord amb la GIEC (20I6: XXIV), necessiti fer servir el català en interaccions entre rols socials amb relacions socials secundàries, objectives, d'àmbit públic i no espontànies.» 
k) Quin és l'estatus teòric de la varietat parlada pels gitanos catalanoparlants? Seria necessari i/o legítim que la SF hi intervingués?

Joan Costa Carreras

Universitat Pompeu Fabra

joan.costa@upf.edu

ORCID 0000-0002-5955-824X

\section{REFERÈNCIES BIBLIOGRÀFIQUES}

Auer, Peter (2005) Europe's sociolinguistic unity, or: A typology of European dialect I standard constellations, dins Nicole Delbecque, Johan van der Auwera \& Dirk Geeraerts (eds.), Perspectives on variation: Sociolinguistic, historical, comparative, Berlín / Nova York, Mouton de Gruyter, p. 7-42.

Badia, Antoni M. (1994) Gramàtica de la llengua catalana. Descriptiva, normativa, diatòpica, diastràtica, Barcelona, Enciclopèdia Catalana.

Bernstein, Basil (I994 [Ia ed. I990]) La estructura del discurso pedagógico. Clases, códigos y control, La Corunya / Madrid, Fundación Paideia / Morata. [Trad. de The structuring of pedagogic discourse. IV: Class, code and control, 1990.]

Block, David (2014) Social class in Applied Linguistics, Londres, Routledge.

Borx, Emili (1998) «La variació social», Caplletra, 25, p. I35-I62.

- (2007) «Papa o papà nostre: un exercici de dialectologia social en català central», Llengua \& Literatura, I8, p. 445-473.

Borx, Emili \& Xavier VILA (1998) Sociolingüistica de la llengua catalana, Barcelona, Ariel. [En línia: <https://www.academia.edu/8887I8I/Sociolingüística_de_la_ llengua_catalana $>$.]

Bourdieu, Pierre (200I) "L'économie des échanges linguistiques ", dins Langage et pouvoir symbolique, París, Fayard, p. 59-I53.

CABré, Teresa (20I6) «De la descripció a la norma: el model de llengua de l'Institut d'Estudis Catalans», dins Gramàtica de la llengua catalana, Barcelona, Institut d'Estudis Catalans, p. XIII-XV).

- (2017) «L'ortografia, element clau de cohesió i estabilitat de les llengües», dins Ortografia catalana, Barcelona, Institut d'Estudis Catalans, p. 9-Io. [Versió digital]

Coseriu, Eugenio (I98I) "Los conceptos de "dialecto", "nivel” y "estilo de lengua" y el sentido propio de la dialectología», Lingüistica Española Actual, 3, p. I-32.

Costa, Joan (I996) «Els “llibres d'estil(s)" i la planificació lingüística», Escola Catalana, 328, p. I6-I9. 
Joan Costa Carreras

És la «variació lingüistica social» una categoria operativa

per a la planificació lingüistica de corpus?

Costa, Joan (2016a) Comunicació "La perspectiva "diastràtica" en la Gramàtica de la llengua catalana. Descriptiva, normativa, diatòpica, diastràtica (1994), d'Antoni M. Badia i Margarit» al X Col-loqui Internacional Problemes i Mètodes d'Història de la Llengua. La complexitat de les llengües, Girona, 27-29 de juny de 20I6. [En línia: <http://diobma.udg.edu/handle/IO256.I/438r >. Les actes estan en premsa a l'editorial John Benjamins.]

- (2016b) «Sobre el "marc de condicions sociolingüístiques favorables» per a la implantació de la normativa lingüística catalana», Caplletra, 6I, p. I23-I52.

- (en premsa) «El "marc de condicions sociolingüístiques favorables": aplicació a la Gramàtica de la llengua catalana (2016)».

GIEC = Institut d'Estudis Catalans (2016) Gramàtica de la llengua catalana, Barcelona, Institut d'Estudis Catalans.

Labov, William (1994) Principles of linguistic change, vol. I: «Internal factors», Oxford, Blackwell

Payrató, Lluís (I996 [ia ed. 1988]) Català col-loquial: aspectes de l'ús corrent de la llengua catalana, [València], Universitat de València.

— (1998) «Variació funcional, llengua oral i registres», dins Lluís Payrató (ed.), ORALMENT: Estudis de variació funcional, Barcelona, Publicacions de l'Abadia de Montserrat, p. 9-33.

- (2010 [Ia ed. 2003]) Pragmàtica, discurs i llengua oral, Barcelona, Editorial UOPC.

$\mathrm{PEO}_{2}$ = Institut d'Estudis Catalans (1999) Proposta per a un estàndard oral 2. Morfologia. [En línia: <https://publicacions.iec.cat/repository/pdf/ooooo039/o0000073. pdf>.]

Pérez Saldanya, Manuel (1998) Diccionari de lingüística, Oliva, Colomar.

Pinto Pajares, Daniel (2016) «Una propuesta de modelo de clase social para la investigación en sociolingüística», dins GRADES Gramática Discurso e Sociedade. DTCL. Documentos de Traballo en Ciencias da Linguaxe Universidade de Vigo. 32 p. [Descarregat d'Academia.edu: <https://www.academia.edu/2923249i/ Una_propuesta_de_modelo_de_clase_social_para_la_investigación_en_sociolingüística>.]

Ros, Joandomènec (2016) «Pròleg», dins Gramàtica de la llengua catalana, Barcelona, Institut d'Estudis Catalans, p. IX-XI.

- (2017) «Pròleg», dins Ortografia catalana, Barcelona, Institut d'Estudis Catalans, p. 7-8. [Versió digital]

RuaIx, Josep (20I7) Intervenció a la «Taula rodona: La Gramàtica de l'IEC, a debat», organitzada per Llengua Nacional el 7 de març de 20I7. [En línia: <https://www. youtube.com/watch?v=igesdEepoP8>: $\min 23.00-30.08$ ] 
Ruiz, Francesc et al. (200I) Diccionari de sociolingüistica, Barcelona, Enciclopèdia Catalana

SARASA, Sebastià (20I4) «Estratificació i classes socials», dins Joan Trullén (dir.), Crisi econòmica, creixement de les desigualtats i transformacions socials. Informe General ECVHPC 20II, p. I28-197. [En línia: <https://iermb.uab.cat/ca/enquestas/ enquesta-de-condicions-de-vida-i-habits-de-la-poblacio-20II/\#openModalı $>$.]

Sarasa, Sebastià, Sergio Porcel \& Lara Navarro-Varas (2013) «Limpacte social de la crisi a l'Àrea Metropolitana de Barcelona i a Catalunya», Papers: Regió Metropolitana de Barcelona: Territori, estratègies, planejament, 56 (2013), p. IO-87. [En línia: $<$ http://www.raco.cat/index.php/PapersIERMB/issue/view/19926/showToc>.] 
